\title{
REQUIREMENTS FOR EDUCATIONAL SUPPORT TOOLS IN VIRTUAL WORLDS
}

\author{
Ishbel M M Duncan \\ School of Computer Science, University of St Andrews, North Haugh, St Andrews, Fife, KY16 9SX, Scotland \\ Ishbel.duncan@st-andrews.ac.uk \\ Natalie J. Coull \\ Department of Computing, University of Abertay, Dundee, DD1, Scotland \\ N.Coull@abertay.ac.uk
}

\begin{abstract}
Keywords: Requirements Evaluation Educational Tools Virtual Worlds
Abstract: Virtual Worlds have been used for online gaming, socialising, business advertising and education. As the educational uses become more sophisticated from early information advertising and teaching resources to simulated laboratory and scenarios, it is necessary to determine requirements for tools and virtual systems to achieve the optimal support possible. This paper discusses the current educational uses of Virtual Worlds and applies this to a set of support requirements derived for an evaluated support tool for learning to program. The result is a layered approach, or checklist, to support learning and evaluation for effective and adaptive online educational support tools including virtual world educational systems.
\end{abstract}

\section{INTRODUCTION}

Virtual Worlds (VW) may have started as a mechanism for young people to enjoy remote socialising or multiple online gaming, but much recent effort has gone into developing online advertising islands for major commercial companies as well as sophisticated techniques for determining, and exploiting, youth culture and fashion. Academics have previously used VLEs to enable teaching and learning but recently, there has been interest in using VWs to situate teaching resources, lectures, online practical sessions, discussions and general information for students.

Virtual Worlds form part of the domain of multiplayer online games, without necessarily the game play. A VW could be entered on an off-line personal computer if the game world does not include interaction with other players, such as in the Sims (http://thesims.ea.com). However, a MultiUser Virtual World (MUVE) such as Second Life implies on-line interaction with other users. MUVEs allow multiple users to access $3 \mathrm{D}$ environments at the same time from different geographical locations. The educational usage of MUVEs has recently become an area of research (Getchell et al., 2006, Salmon, 2009, Edirisingha et al., 2009, Oliver and Carr, 2009, Duncan et al., 2012) with a large emphasis on Second Life (www.secondlife.com). In 2010 over 750,000 unique users spent over 105 million hours online with Second Life (SL). It is a major supporter of education with over 700 international educational institutions residing within its islands, or server resource centres. Separately, use of the Internet has grown to over 2,267 Million users worldwide in December 2011, 32.7\% of the world's population. The biggest online populations are in Asia, 1,016 Million, and Europe at 500 Million users. The biggest penetration of users is in North America with $78.6 \%$ of its population active online at 273 Million out of 347 Million users (www.internetworldstats.com). SL penetration is therefore small at less than $1 \%$. However, any usage for educational benefit has a potentially large audience.

A Virtual Learning Environment (VLE) is commonly used as a virtual environment for supporting educational documents, uploading assessments and grades as well as supporting communication between students and lecturers or 
tutors with a chat mechanism (Jenkins et al., 2005). Whereas VLEs are dedicated to educational support, VW and MUVEs are still commonly used for gaming and or socialising via the use of avatars. They too may support chat communication and can further the student experience by visualising or modelling real or imagined world events, scenarios, buildings or sites. For example, Second Life has islands dedicated to Higher Education Institutions which support simulated archaeological digs, architectural building development, language teaching and algorithm display.

\section{CURRENT STATE OF THE ART}

Many articles have been written on the different aspects of the educational uses of MUVEs (Akpan and Brooks, 2005, Childs, 2007, Dawley, 2009, Mason, 2007). Duncan et al. ( Duncan et al., 2012) investigated 65 articles on MUVEs, Virtual Worlds and VLEs and noted six different categories of published work. These are:

- Educational Activities

- Learning Theories

- Learning Environments

- Supporting Technologies

- Applicable Age Grouping

- Research Areas

Educational activities included virtual field work, virtual laboratories, collaborative construction, collaborative simulations, role playing, game based learning, virtual quests as well as lectures or lessons. Collaborative Simulation was the most common with nearly half of the reviewed literature and collaborative constructional activities were $24 \%$. Game based learning, virtual quests, role play and lectures or lessons scored $10 \%$ to $20 \%$ each in the reviewed literature. Most articles discussed higher or further education.

Learning Theory refers to the philosophy behind the educational approach. According to Twining (Twining, 2009), experiments have been performed by integrating different learning theories into educational activities. Constructivist techniques such as problem and game based learning are often used in MUVEs because they allow for experiential learning. Groupwork scenarios can build on team strengths and interests and help develop skill and confidence levels. Games allow for interactivity and discussion. Collaborative tools such as wikis, blogs, co-authoring and social networking occur in MUVEs. Direct instruction, or didacticism, is used via online lectures for colleges and universities and webinars, web based seminars, are common in industry. In terms of student collaboration, didacticism is at one end of a scale up to knowledge based constructivism at the most student active end of the scale. Problem based learning, collaborative, experimental, instructional, constructivist, didactic and interactive learning were all identified in the reviewed literature. Collaborative work was mentioned in more than $50 \%$ of papers, and knowledge building in $40 \%$. Surprisingly problem based learning was only mentioned in $14 \%$ of publications.

The Learning Environments category contains the virtual environments that are used by the researchers in the reviewed literature. There were basically two sub-categories; Web 2.0 based VLEs such as Moodle, Blackboard and WebCT and 3D web technologies such as Second Life and Active Worlds (www.activeworlds.com).

The Supporting Technologies category includes Voice over IP (VOIP), stream video/audio and Chat and Instant Message (IM). Head-up displays and immersive technologies can also be included here. The use of the technologies varies; publishing, programming or communication are the obvious functionalities but navigation, mapping and storage techniques are also included here.

The Applicable Age Grouping demonstrates that online education is not just for the young. Under $18 \mathrm{~s}$ should use Teen Second Life. Experimental projects and designed activities are different for the separate age groups; more audio than keyboard support might be used for the elderly as opposed to the young. Rix and Twining (Rix and Twining, 2007) define three levels of pre-18, post-18 and lifelong. Duncan et al. suggest primary, secondary, further and higher education followed by lifelong learning and general education.

The last category includes all the current research in the field. Researchers are working on aspects of identity, embodiment and geo-spatial representation as well as usability, deployment, knowledge-passing and co-ordination in a learning environment. 


\section{REQUIREMENTS FOR LEARNING SUPPORT TOOLS}

In work which investigated the requirements necessary for a learning to program support tool (Coull and Duncan, 2011), the result was a set of ten requirements that programming support tools should have. Educational tools or mechanisms in Virtual Worlds will not necessarily be for aiding the development of coding, but the generic requirements are undoubtedly similar (see later in 3.1). Students need guidance and confidence to develop their learning online as well as directed, specific support related to the task on hand. To support a student the applicable technologies, such as audio, video or the VLE or access, have to be installed and be reliable. Further they have to be constantly updated to maintain up-time when new operating systems or video cards etc. are installed on servers, or clients, the network. Further, context relevant physical support must be available, such as virtual reality glove sets, joysticks, 3D projections etc. when students are using virtual archaeological digs or wandering through reconstructions of ancient palaces.

In programming terms the ability to write a correct program depends on four levels of required knowledge. The first two are known as program formulation in which the syntactic and semantic knowledge of a program allows students to develop a mental model of what is happening in code. The higher levels of required knowledge are known as problem formulation; schematic knowledge is the ability to recognise the patterns or plans to form a correct solution and strategic knowledge is the ability to create these plans. Hence a novice moves from program formulation through to problem formulation.

It is proposed that a similar framework of required knowledge is applicable to working in Virtual Worlds. One level is the requirement that students understand the context of the task expected of them - attendance at a lecture, groupwork, a constructivist activity etc.. Each of these will have their own expected level of understanding, skill sets and pre and post conditions for successfully performing the learning task. A secondary level is the VW understanding and support requirements taken from the technology used and understanding of the computational environment. If a student does not understand how to navigate through the VW or store information or search for group members, then they will be unable to successfully complete the given task. Also, students must be able to identify the constructs they require, and perhaps the communications, to solve their given task and further, to place these constructs together in an order which allows a solution to be reached.

Hence, there are four levels of knowledge a student must have in order to complete a task in a VW:

- Understand the world context and what the required task is

- Understand how to use the functional aspects of the world, the constructs available to them

- Identify and manipulate the constructs they need to perform the given task

- Order these constructs to attain a goal

The required knowledge could be viewed as basic manipulation or usage knowledge (the first two bullet points) and schematic and strategic knowledge, the last two bullet points, where patterns are recognised and formed into a directed goal.

\subsection{Requirements}

In the Coull and Duncan paper (Coull and Duncan, 2011) the authors argue for ten emergent requirements for a support tool for programming support. These are listed in Table 1, with the parenthesis in column 2 indicating programming specific requirements which would not necessarily be applicable in a VW task.

Table 1: Core Requirements of an Effective Support Tool

\begin{tabular}{|c|c|}
\hline Requirement & Description \\
\hline $\begin{array}{l}1 \text { (levels of } \\
\text { support) }\end{array}$ & $\begin{array}{l}\text { Present (both standard compiler and } \\
\text { enhanced) support concurrently }\end{array}$ \\
\hline 2 (linkage) & $\begin{array}{l}\text { Link to teaching resources as a } \\
\text { means of information delivery and } \\
\text { student-tutor dialogue }\end{array}$ \\
\hline 3 (errors) & $\begin{array}{l}\text { Identify and advise on commonly } \\
\text { observed (semantic) errors }\end{array}$ \\
\hline 4 (key constructs) & $\begin{array}{c}\text { Embody knowledge of key } \\
\text { constructs needed to solve a } \\
\text { problem }\end{array}$ \\
\hline $\begin{array}{l}5 \text { (construct } \\
\text { relationship) }\end{array}$ & $\begin{array}{l}\text { Embody knowledge of the } \\
\text { relationships between the constructs } \\
\text { needed to solve a problem }\end{array}$ \\
\hline $\begin{array}{c}6 \text { (dissemination } \\
\text { strategy) }\end{array}$ & $\begin{array}{l}\text { Knowledge should be disseminated } \\
\text { to students in successive stages }\end{array}$ \\
\hline $\begin{array}{l}7 \text { (variant } \\
\text { solutions) }\end{array}$ & $\begin{array}{c}\text { Ensure that the knowledge } \\
\text { accommodates variant solutions, if } \\
\text { they exist }\end{array}$ \\
\hline 8 (varied & Provide support for different \\
\hline
\end{tabular}




\begin{tabular}{|c|c|}
\hline problems) & problems \\
\hline $\begin{array}{c}9 \text { (Support } \\
\text { reduction) }\end{array}$ & $\begin{array}{c}\text { Support may be progressively } \\
\text { reduced over the teaching period }\end{array}$ \\
\hline 10 (Volition) & $\begin{array}{c}\text { Use of the tool must be voluntary } \\
\text { on the part of the student }\end{array}$ \\
\hline
\end{tabular}

The descriptions of the generic support tools indicate that the tool must be voluntary (10), be provided concurrently with the normal system support (1) and be progressively reduced throughout the teaching period (9) so that students do not become reliant on it. There should be links to teaching resources such as lectures, laboratory exercises, tutorial sheets and perhaps a chat or email mechanism to the course tutors (2). Knowledge of the key constructs in the system, or world, must be given and practiced (4) and the relationships between those constructs must be understood during the experience (5). This knowledge may be disseminated via a staged process (6). As the course or module is developed, different tasks should be embodied within the VW so that it is not a one-off experience (8) and when marking or grading student work, tutors, or an automated grader, should take into account that solutions may be varied (7). On the functional support side, the system or at worst, an email account, should be available for logging faults, either with the computational aspects, the physical support, the tasks given or semantic problems to do with the rendering etc. (3). These can therefore be dealt with by the tutors and support staff.

The requirements for learning support are therefore divided between tool support, task support and learning support. These could then be codified as:

- Tool support - Present tool alongside original functional support, make the use voluntary, reduce the support throughout the course lifetime and collect (and fix) errors.

- Task support - Knowledge of constructs and the relationships between them, if any, must be given.

- Learning support - Links to teaching resources should be given and knowledge should be disseminated at appropriate intervals, varied tasks should be attempted and grading should take into account the varied successful outcomes.

Each of these are necessary to allow students to learn virtually and to progress through given tasks in a virtual world. However a task is envisaged or developed it has to be graded and as with any qualitative analysis in a computational environment, this has to be tackled via a variety of evaluation procedures.

\section{EVALUATION ISSUES}

Evaluation is a difficult task and it can often take a significant number of hours to do when the product is not as straightforward to analyse as a functional code procedure. As with anything visual, a measure of qualitative analysis has to be used alongside quantitative analysis. Steinkuehler and Duncan (Steinkuehler and Duncan, 2008) state that some user posts on a World of Warcraft forum (www.worldofwarcraft.com) displayed an evaluative position where "knowledge is an open-ended process of evaluation". Some users demonstrated an absolutist approach treating knowledge as "objective, certain and .. accumulative" whereas others were relativistic and treated the world as subjective as in "to each his own". Therefore it can be concluded that this type of qualitative analysis has to be garnered from questionnaires, interviews and posts and is difficult to analyse because of its divers nature.

Gabbard et al. (Gabbard et al., 1999) describe a methodology for evaluating virtual environments using user task analysis, expert guidelines-based evaluation, formative user-centered evaluation, and summative comparative evaluations. They discussed cycles of evaluation with an expert on hand to determine guide-lines for usage. Most of this work considered usability characteristics and attempted to determine summative scores for formats or placements of information. de Feitas et al. (de freitas et al., 2009) advocate incremental testing alongside evaluation of virtual world learning experiences. Their work used an inductive methodology to construct theories and explanations based upon observations and survey data. They monitored students and used surveys, specifically using chat logs and video footage. They set out to test their Four Dimensional Framework which includes a learner specific evaluation (profile, role, competency), the pedagogy (associative, cognitive and social/ situative), the representation (fidelity of design to implementation, interactivity, immersion) and the context (environment, access to learning and supporting resources).

Consequently, evaluation of virtual worlds for learning require a multi-faceted approach wherein usability guidelines have to be stated and then measured for fidelity as well as for content, suitability, affectiveness, technical and pedagogical appropriateness. Functionality of the required and student developed solution have to be compared and further, the physical support side has to be considered in terms of the network speed, server 
connection and up-time and standards etc.. Therefore a levelled approach is advocated as in section 3.1, but including the network layer:

- Network support - Network statistics must be gathered and compared to a standard or expected level of quality.

- Tool support - The underlying tool and/or virtual world must be evaluated to determine if the necessary learning constructs, the required learner support and ability to add learning or virtual constructs exists.

- Task support - The virtual constructs to engender a learning experience must exist or be able to be built with given or constructed learning.

- Learning support - The required knowledge must be linked to or in evidence.

Further work on evaluating specific learning experiences in Second Life and other virtual worlds is necessary to create a taxonomy of issues and determine if a generic support framework can be determined from the above. Effectively the computational side, the network and the virtual world support, must be evaluated by quantitative analysis based on quality of service and usability. The learning task requires qualitative analysis based on pedagogy and pre and post knowledge derived from questionnaires, interviews and logging information.

The core requirements mentioned above are currently undergoing evaluation in a variety of virtual world learning scenarios and systems and the results will be recorded in due course.

\section{CONCLUSIONS}

Virtual Worlds are increasingly being used for teaching with constructivist and collaborative learning being the common approaches taken. Consequently it is imperative to develop requirements check-lists and evaluation mechanisms for the learning aspects as well as the virtual world, any support tools and the underlying system requirements.

The paper has outlined two papers on the educational uses of virtual worlds and the generic requirements for a support tool. In marrying the support requirements to the uses for virtual worlds a layered approach to determining requirements and evaluating virtual worlds for educational purposes emerges in which both qualitative and quantitative analysis is required at network, system, virtual world, learning task and user levels.

\section{REFERENCES}

Akpan, J. I. \& Brooks, R. J. Year. Experimental Investigation of the Impacts of Virtual Reality on Discrete-event simulation. In: Kuhl, M. E., Steiger, N. M., Armstrong, F. B. \& Joines, J. A., eds. Winter Simulation, 2005 Orlando, Florida. ACM, 1968-1975.

Childs M. 2007. Real Learning in Virtual Worlds. Warwick Interactions Journal, 30, 38-45.

Coull N. J. \& Duncan, I. 2011. Emergent Requirements for Supporting Introductory Programming. ITALICS - Innovation in Teaching and Learning in Information and Computer Sciences, HEA e-journal.

Dawley, L. 2009. Social Network Knowledge Construction. On the Horizon, 17, 109-121.

De Freitas, S., Roebolledo-Mendex, G., Liarokopakis, F., Magoulas, G. \& Poulovassilis, A. 2009. Learning as Immersive Experiences: Using the FourDimensional framework for Designing and Evaluating Immersive Learning Experiences in a Virtual World. British Journal of Educational Technology, 41, 6985 .

Duncan, I., Miller, A. \& Jiang, S. 2012. A taxonomy of virtual worlds usage in education. British Journal of Educational Technology, to appear 2012.

Edirisingha, P., Nie, M., Pluciennik, M. \& Young, R. 2009. Socialisation for learning at a distance in a 3-D multi-user virtual environment. British Journal of Educational Technology, 40, 458-479.

Gabbard, J. L., Hix, D. \& Swan II, J. E. 1999. UserCentered Design and Evaluation of Virtual Environments. IEEE Computer Graphics and Applications, 19.

Getchell, K., Miller, A., Allison C., Kerbey, C., Hardy R., Sweetman, R., Crook, V. \& Complin, J. 2006. The LAVA Project: A Service Based Approach to Supporting Exploratory Learning. IADIS International Conference WWW/Internet Murcia, Spain

Jenkins, M., Browne, T. \& Walker, R. 2005. VLE surveys: A longitudinal perspective 
between March 2001, March 2003 and March 2005 for higher education in the United Kingdom. UCISA.

Mason, H. Year. Experimental Education in Second Life. In: Livingston, D. \& Kemp, J., eds. SLCC' 07, 24-26 Aug. 20072007 Chicago. 14-18.

Oliver, M. \& Carr, D. 2009. Learning in virtual worlds: Using communities of practice to explain how people learn from play. British Journal of Educational Technology, 40, 444-457.

Rix J. \& Twining P. 2007. Exploring education systems: towards a typology for future learning? Educational Research, 49, 329341.

Salmon G. 2009. The future for (second) life and learning. British Journal of Educational Technology, 40, 526-538.

Steinkuhler C. \& Duncan, S. 2008. Scientific Habits of Mind in Virtual Worlds. Science Education Technology, 17.

Twining, P. 2009. Exploring the Educational potential of Virtual Worlds - Some Reflections From the SPP. British Journal of Educational Technology, 40, 496-514. 